\title{
Developing Buy-in for Positive Behavior Support in Secondary Settings
}

\author{
Hank Bohanon \\ Loyola University Chicago, hbohano@luc.edu \\ Meng-Jia Wu \\ Loyola University Chicago, mwu2@luc.edu
}

Follow this and additional works at: https://ecommons.luc.edu/education_facpubs

Part of the Education Commons

\section{Author Manuscript}

This is a pre-publication author manuscript of the final, published article.

\section{Recommended Citation}

Bohanon, H. \& Wu, M. (2014). Developing buy-in for positive behavior support in secondary settings. Preventing School Failure, 58 (4), 1-7. 223-229. doi: 10.1080/1045988X.2013.798774

http://ecommons.luc.edu/education_facpubs/17/

This Article is brought to you for free and open access by the Faculty Publications and Other Works by Department at Loyola eCommons. It has been accepted for inclusion in Education: School of Education Faculty Publications and Other Works by an authorized administrator of Loyola eCommons. For more information, please contact ecommons@luc.edu. cc) (†) $\Theta$

This work is licensed under a Creative Commons Attribution-Noncommercial-No Derivative Works 3.0 License. (c) Routledge, 2014. 
Running head: SUPPORTING ADOPTION OF POSITIVE BEHAVIOR SUPPORT

Developing Buy-In for Positive Behavior Support in Secondary Settings

\author{
Hank Bohanon \\ Loyola University Chicago \\ School of Education \\ Lewis Towers \#1052 \\ 820 N. Michigan Ave. \\ Chicago, IL 60611 \\ 312-915-7099 \\ Fax 312-915-6660 \\ hbohano@luc.edu
}

(correspondence should be directed to Dr. Hank Bohanon)

and

Meng-Jia Wu

Loyola University Chicago

School of Education

Lewis Towers \#1040

820 N. Michigan Ave.

Chicago, IL 60611

312-915-7086

Fax 312-915-6660

mwu2@luc.edu 
SWPBS in High Schools 2 


\section{Role of the funding source}

Development of this publication was supported in part by a subcontract from the U.S.

Department of Education, Office of Safe and Drug Free Schools (R324A070157). Opinions expressed herein are our own and do not necessarily reflect the position of the U.S. Department of Education, and such endorsements should not be inferred.

\section{Acknowledgements}

The authors also appreciate the support of the Illinois Positive Behavior Support Network for coaching and data collection. Further, they appreciate the support of the current and former staff members of the Center for School Evaluation, Intervention, and Training at Loyola University of Chicago for their role in the development and implementation of the project.

Please cite as

Bohanon, H. \& Wu, M. (In Press). Developing buy-in for positive behavior support in secondary settings. Preventing School Failure. 


\begin{abstract}
Based on the implementation of school-wide positive behavior supports (SWPBS) in high schools, the current study examined the effect of supporting buy-in through conducting needs assessments and focused professional development for high school staff when implementing SWPBS. The effectiveness of the two additional items was investigated using two treatment schools and two comparison schools. The hypothesis was that schools with enhanced support would implement SWPBS better and student office discipline referrals (ODRs) would drop due to the better implementation. Overall, the results showed the treatment schools improved in fidelity and demonstrated significant improvement in numbers of ODRs. In contrast, both comparison schools decreased in fidelity and none demonstrated significant changes in ODRs. Suggestions for practice and future research are provided.
\end{abstract}

\title{
Keywords:
}

Positive Behavior Support

High Schools

Stages of Implementation

Buy-In

Professional Development

School Change 


\section{Introduction}

Schools today are facing significant challenges related to student discipline (National Center for Education Statistics [NCES], 2010). Reactive approaches (e.g., suspension, expulsion) to these concerns can limit student-to-school connections (Gregory \& Weinstein, 2008), and they may negatively affect relationships between teachers and students who are most at-risk of failure (Matjasko, 2011). Fortunately, there are evidenced-based practices (EBPs) that can address these behavioral concerns in a less punitive way (Bradshaw, Mitchell, \& Leaf, 2010; Horner et al., 2009). Although individuals who wish to reform discipline practices can encourage the implementation of EBPs, they may face resistance due to concerns about contrasting beliefs, increased time requirements, and extensive training efforts (Bambara, Goh, Kern, \& Caskie, 2012; Lohrmann, Martin, \& Patil, 2013). To address these issues, change agents must consider the settings where the change will occur (Biglan, 1995) across stages of implementation (State Implementation \& Scaling-up of Evidence-Based Practices Project [SISEP], 2012).

The initial stages of program implementation include exploration (e.g., understanding the need for change, developing champions and stakeholders), installation (e.g., establishing resources to increase future fidelity), and initial implementation (e.g., learning about the model through first attempts; Fixsen, Blase, Horner, \& Sugai, 2009). Key to this process is to establish a common vision for the rationale for the intervention (Fixsen \& Blasé, 2009) and to create a sense of urgency for the change (Kotter, 1995). This is accomplished through understanding the language, terminology (Hunt \& Sullivan, 1974), and priorities (Knight, 2002) of the setting. These approaches play an important role in addressing buy-in for staff related to EBPs. 
According to Detrich, Keyworth, and States (2007), resistance to the implementation of EBPs occurs when people are called to action before there has been a clear validation of a need and a shared perception of discontent with current practice. They explained that an audience must be created that will use information related to the need for change. Providing relevant data to those being asked to change (Fixsen et al., 2009) can lay the foundation for effective implementation of EBPs to improve practices and outcomes. To ensure early and critical success of EBP implementation, a focus should be given to factors that affect the intervention including implementation stakeholders (e.g., teachers, administration), practices, organizational systems, and the ultimate stakeholders (e.g., students; Detrich et al., 2007).

The EBP addressed for this example is schoolwide positive behavior support (SWPBS; Horner, Sugai, \& Anderson, 2010; Sugai et al., 2010) at the high school level. The implementation of SWPBS has been related to decreases in teacher burnout (Ross, Romer, \& Horner, 2012) and decreases in disciplinary expulsions for high school students (Vincent, 2011). Implementation of universal supports at the high school level has lead to improved student discipline outcomes (Bohanon et al., 2012), classroom environments (Hawkins \& Heflin, 2011) and the reduction of tardiness (Tyre, Feuerborn, \& Pierce, 2011), a critical issue in secondary schools (Flannery, Fenning, Kato, \& Bohanon, 2011). While research supports the approach of taking time to develop readiness in high schools when implementing SWPBS (Flannery, Guest, \& Horner, 2010), few studies have used systemic analysis to determine its effectiveness. Moreover, there are sparse data available involving the use of the needs assessment and focused professional development to support readiness for SWPBS in high schools. 
The use of needs assessment and focused professional development may serve as a catalyst for transitioning high schools through the Exploration and Installation and Initial Implementation stages. Needs assessment may enhance buy-in (Exploration) by helping external staff to determine if the EBP fits needs of the setting (SISEP, 2012) through understanding the emic (i.e., inside) perspective of the school staff (Guba \& Lincoln, 1994). Focused professional development may promote initial implementation because it is a mechanism to define the terms and processes of the intervention within the local context (Biglan, 1995). In other words, focused professional development allows school personnel to identify their school's own specific needs and connect SWPBS with their goals. Awareness of the perceptions of SWPBS (or the school climate in general) may help external support providers prepare to address concerns in advance of training (Lohrmann, Martin, \& Patil, 2013). It also may increase the likelihood that staff are more prepared to carry out specific tasks related to SWPBS. High levels of errors can be triggers for future problems by adding an aversive component to the approach or reinforcing avoidance of the approach on the part of the staff (Munk, 1994). Focused professional development can decrease the number of errors teachers make when initially implementing SWPBS skills.

Purpose

This study addressed two goals related to the investigation of the effectiveness of SWPBS. One question for this study was to investigate whether SWPBS fidelity was higher for treatment schools that explicitly addressed the specific stages of exploration, installation, and implementation than comparison schools that did not, as measured by the School-wide Evaluation Tool (SET; described below). Two approaches were specially used to address these 
stages: (a) needs assessment, and (b) focused-professional development. Needs assessments for the purpose of this study was defined as the systematic inquiry of readiness through focus group like interviews with key stakeholders. Focused professional development for this study included training that was targeted in content (e.g., SWPBS) and through examples (e.g., high school specific) to address an area of systems preparation (e.g., healthy functioning) for teams. The second question was to determine if treatment schools had a greater occurrence of significant reductions in office discipline referrals (ODRs; described below) than the comparison schools.

\section{Methods}

The research design for this study was quasi-experimental with purposively selected treatment and comparison schools. Repeated measures on ODRs were collected in the targeted schools to determine and compare any changes over time related to outcomes. Sampling

Schools included in this study were identified by using purposive sampling (Patton, 1980) as described below. An effort was made to include schools from four regions within a large Midwestern state and to address maximum variation between schools. For inclusion, schools had to be implementing SWPBS at some level as indicated by the submission of fidelity data. Serial nomination was used in that leadership from the state SWPBS network provided suggestions on high schools that were implementing SWPBS and would represent a variety of settings. Four schools met the final requirements for analysis (two treatment and two comparison). Demographic information for the study is included in Table 1. $<$ Insert Table 1 here $>$

Measures 
The SET was used as a measure of fidelity of implementation for this study. Horner et al. (2004), suggested that the SET can be a reliable and valid tool to assess the need for training, determine the impact of professional development for SWPBS, track the sustained use of SWPBS at the school-wide level, and identify local strategies for improving SWPBS outcomes. Recent research on the SET reported that the SET had total reliability coefficients at the high school level of $r=.899$ (Vincent, Spaulding, \& Tobin, 2010). The SET in this study was conducted by trained personnel from the state SWPBS network using a standardized protocol. These individuals were typically trained by shadowing evaluators considered to be SET trainers and by collecting concurrent data until their reliability was within $80 \%$ reliability of the trainer. In most cases, the SET assessments included two independent raters trained by the state SWPBS network to ensure reliability. These assessments were completed in the late fall or early winter.

Outcomes regarding the impact of the implementation of SWPBS were measured using ODR data. Office discipline referral data are commonly used as (a) an indicator of school climate, (b) a measure of the effectiveness of SWPBS implementation (Irvin, Tobin, Sprague, Sugai, \& Vincent, 2004), and (c) a mechanism for determining the behavioral support needs of the school (Irvin et al., 2006; Scott \& Barrett, 2004). The mean ODRs for this study were adjusted to provide consistent metrics for measuring impact across sites by using the total ODRs per day, per month, per 100 students, and per average daily enrollment. Schools were required to report ODR data through the use of a monthly data report. Consistent data were available for all schools between the months of September and March.

Procedures 
Intervention for the treatment schools lasted two years: year one (2007-2008) focused on exploration (e.g., district level meetings, conducting needs assessments, providing district and school-level feedback). The needs assessment sessions utilized a style similar to those used in focus groups (Krueger \& Casey, 2000) and are available at http://www.hankbohanon.net. The results of the needs assessment were summarized (see Table 2 for an example) and presented back to the school level leadership team by project staff. Year two (2008-2009) consisted of installation (e.g., adapted universal training with additional high school components, training school teams on effective teaming and leadership) and initial implementation (e.g., providing ongoing coaching to build level teams, reflecting on successes and needs based on data). Examples from the training, including documents used for needs assessment can be found at http://www.hankbohanon.net. Figure 1 provides a time line depicting the implementation process for the treatment schools. Both treatment and comparison schools had been exposed to training and coaching on universal SWPBS prior to this study. This training included: district team meetings, develop team of leadership team, self-assessment, develop of teaching matrix, teaching system (e.g., lesson plans), acknowledgment systems, policies and consequences for discipline, and using ODR systems for decision making. This training had been led by state and district level external coaches trained by the statewide network.

$<$ Insert Figure 1 here $>$

$<$ Insert Table 2 here $>$

Data Analysis

Descriptive statistics based on the SET data were used to address the first research question regarding whether schools that were part of the treatment group had higher levels of 
implementation of SWPBS than comparison sites. Data were collected on the SET for all sites for 2007-2009. The Change Point Test (Siegel \& Castellan, 1998) was used to answer the second research question determining whether there were significant reductions in ODRs in treatment and comparison schools (Bohanon et al., 2012).

Results

The first question in this study considered if treatment schools would have higher levels of implementation of SWPBS than comparison sites, as measured by the SET. The average total SET scores for $2007-2008$ were $92 \%$ for treatment (T) school one, $61 \%$ for $\mathrm{T} 2,53 \%$ for comparison (C) school one, and 78\% for C2. The average total SET scores for 2008-2009 were $99 \%$ for $\mathrm{T} 1,74 \%$ for $\mathrm{T} 2,36 \%$ for $\mathrm{C} 1$, and $56 \%$ for $\mathrm{C} 2$. The treatment schools had an increase of an average of 10 percentage points on their average total SET scores between 2007-2008 and 2008- 2009. The comparison schools had a decrease of an average of 20 percentage points on their average total SET scores between 2007-2008 and 2008-2009. It would appear that the treatment schools were able to demonstrate greater increase in implementation in contrast to comparison schools.

Examination of the sub-scores of the SET indicated that overall, the treatment schools maintained or increased implementation scores in almost all categories. The greatest area of improvement for the treatment schools was in the areas of addressing violation systems $(+44 \%$ points) and district level support ( $+25 \%$ points). T1 had improvements in the areas of addressing violation systems and the leadership team between years. There were slight decreases for $\mathrm{T} 2$ in the areas of teaching expectations and leadership across years. Comparison schools maintained or decreased their implementation in all areas of the SET except for defining 
expectations. The greatest decrease for comparison schools was the in the area of leadership ($42 \%$ points) and monitoring and evaluation systems (- $48 \%$ points) between years.

The second question considered if the treatment schools had more occasions of significant reductions in ODRs than comparison schools. The adjusted mean ODRs for treatment sites was $2.78(S D=1.2,2007-2008)$ and $1.69(S D=.77,2008-2009)$. The adjusted mean ODRs for comparison sites was $2.17(S D=1.03,2007-2008)$ and $2.38(S D=1.44$, 2008-2009). The treatment schools started out at a higher rate of ODRs per month on average than comparison sites. The treatment schools exhibited a decrease (-39\%) in adjusted mean ODRs between 2007-2008 and to 2008-2009, while the comparison schools demonstrated an increase $(+10 \%)$ during the same time period. In general, there appeared to be an overall decrease in the treatment schools' adjusted mean ODRs from 2007-2008 to 2008-2009, and an increase for comparison schools during the same period.

To determine whether there were significant changes in adjusted mean ODRs over time, Change Point Tests were conducted (Bohanon et al., 2012). Both treatment schools demonstrated a significant change point in March 2008, in the form of a decrease in adjusted mean monthly ODR rates $(z=2.30, p=.022$ for T1; $z=3.07, p=.002$ for T2 $)$. One of the comparison schools $(\mathrm{C} 1)$ demonstrated a month where a change point was identified, but it was not significant $(z=1.09, p=.28)$. No significant increases in adjusted mean monthly ODR rates were identified for either treatment or comparison schools. There did not appear to be any adverse events associated with treatments provided in this study.

\section{Discussion}


This study addressed two goals related to the investigation of the effectiveness of SWPBS. The first question was to investigate whether SWPBS fidelity was higher for treatment schools that explicitly addressed the specific stages of exploration, installation, and implementation than comparison schools that did not, as measured by the SET. It would appear that, overall, schools that participated in the needs assessment process and received additional training had overall increased levels of implementation. The results for T1 for the average SET score and subcomponents were overall higher than its comparison school. T2 had positive outcomes for fidelity, particularly in overall SET score as compared to its comparison school. However, the slight decrease in the subcomponent for leadership was somewhat concerning. During the initial year of the project, there appeared to be a more effective leadership team for this school (T2). During 2008-2009 considerable time was given to address the administration's concerns (e.g., teaching expectations took too much time from instruction, review of schoolwide data delayed access for supports for students with intense needs). This resulted in less support (e.g., time) for the team and the internal coach to fully implement the project. It would appear that a needs assessment and focused training program designed to improve support and functioning of the team may not be powerful enough to address decreases in support from the administration. Given more time, perhaps the district leadership team could have provided support in terms of addressing the concerns of the building principal. Future research should focus on addressing initial and long term staff and administrator buy-in for EBPs (Lohrmann, Martin, \& Patil, 2013).

The second question considered whether treatment schools would have more significant improvements in problematic behavior and discipline outcomes as measured by adjusted mean 
ODRs. Each of the treatment schools had a significant change point decrease for their ODRs during the course of the study. Based on the Change Point Test, one of the comparison sites did have an identifiable, yet not statistically significant, change point in the downward direction of the slope. The results appear to support that the schools participating in needs assessments and professional development for teams, above standard training, had more significant decreases in ODRs than comparison schools.

The results of this research appear to be similar to other studies (Bohanon et al., 2006; Bohanon et al., 2012) regarding schools that involved a needs assessment as part of establishing the need for the intervention (Kotter, 1995). To our knowledge, studies before this one have not made use of comparisons schools to determine if additions such as needs assessments and focused professional development for teams would lead to high levels of implementation and improved behavioral outcomes.

There seem to be several implications regarding this work. These outcomes support the assertion by Flannery et al. (2010) that special consideration of program-level enablers, such as distributing leadership, specifying role assignments, and taking time to explore needs based on data, may be effective in increasing the success of teams. Further, it appears that readiness (Kotter, 1995) for the process, "can be developed and sustained with thoughtful activities that are sensitive to individuals' needs for relevant information and involvement in decision making" (Fixsen et al., 2009, p. 4). These outcomes can be obtained by: (1) planning for change (e.g., assessing key features in place for EBP, adapting features to local context), (2) facilitating communication (e.g., rapid feedback cycles to make adjustments), (3) implementation (e.g., develop capacity through training, coaching, monitoring fidelity and outcomes), and (4) data 
collection and reporting (e.g., collecting fidelity and outcome data, accessibility of data for all team members).

\section{Limitations}

There are several limitations for this present study. First, no data were collected on the integrity of the training the schools had already received for either group; however, both treatment and comparison schools had been trained utilizing a consistent professional development curriculum. The individuals who provided training for each group (both before and during the study) were prepared for this work by a training of trainers model using standardized materials and procedures. While not ideal for clinical trials, this format reflects the training methods of applied technical assistance programs.

Second, inter-rater reliability data were not collected as a part of the fidelity measures. Further, the data collectors were not blind to the conditions of the study. However, when possible, two raters were used to generate an agreement for the final score. In addition, all raters used the same manual and had received training on the fidelity instrument (Gersten et al., 2005). Third, due to the nature of the applied condition of the study, it is difficult to determine what treatment component(s) (or other factors) may have been related to the significant changes in the slope of the ODR data. Also, it is possible that substantive decreases and maintained lower levels of ODRs were sustained by additional training and support. This is similar to findings by Tay (2001), who found that awareness of a policy may lead to actual decreases in a targeted outcome and that implementation of policy ensures that the desired outcomes are maintained. Further, the team's review of ODR data on a regular basis could have changed their practices, similar to the effects of a self-management procedure. Given the higher rate of ODRs for the 
treatment schools, the trend for these schools was more likely to show a reduction than for comparison schools due to regression to the mean. Further, it is plausible that reductions in ODRs were a result of teachers not referring students to the office due to a perception that this action was not welcomed. Alternatively, treatment schools were provided with training that when they their shared their ODR data, they were to pre-correct the staff that writing an ODR was not undesirable. The school teams simply hoped the staff would have fewer reasons to write them. It is also possible that the findings of significance were related to the data range being limited to August through March. However, this limitation was counter balanced for both treatment and comparison schools. Finally, additional outcome measures were not used in this study to determine the impact on actual student behavior.

Future Directions and Next Steps

Future projects of this type should use measures of treatment integrity for training and perhaps rotate training personnel across conditions (Gersten et al., 2005). Further, future data collection processes should account for differences in ODR data collection systems by clearly analyzing reliability procedures across schools. These sites could use a checklist for readiness to track the level of complimentary data collection procedures required for accurate data collection. Anomalies could then be reported as a part of the results section. Outcome measures beyond ODRs also should be used to determine the impact SWPBS.

\section{Conclusion}

In this study, we attempted to determine if the addition of needs assessment and focused professional development for leadership teams would improve the performance of schools implementing SWPBS. It appears that the addition of needs assessments and training may be 
related to improved outcomes for staff and students. Considerable research is needed to determine which factors and training components may lead to the most effective outcomes for all students. However, these results perhaps support the adoption of strategies that address the readiness of schools and support changes in staff behavior over time.

\section{Author Notes}

- Hank Bohanon is an associate professor at the Loyola University Chicago. His current research interests are positive behavior support, high school reform, social and emotional learning, response to intervention, and school mental health.

- Meng-Jia Wu is an assistant professor at the Loyola University Chicago. Her current research interests are meta-analysis, longitudinal data set analysis, and analysis of nonlinear data.

\section{References}

Bambara, L. M., Goh, A., Kern, L., \& Caskie, G. (2012). Perceived barriers and enablers to implementing individualized positive behavior interventions and supports in school settings. Journal of Positive Behavior Interventions, 14(4), 228-240. doi: $10.1177 / 1098300712437219$

Biglan, A. (1995). Changing cultural practices: A contextualist framework for intervention research. Thousand Oaks, CA: Context Press.

Bohanon, H., Fenning, P., Hicks, K., Weber, S., Their, K., Akins, B., Morrissey, K., Briggs, A., Bartucci, G., Hoeper, L., Irvin, L., \& McArdle, L. (2012). Case example of the implementation of schoolwide positive behavior support in a high school setting. Preventing School Failure, 56(2), 92-103. doi: 10.1080/1045988X.2011.588973. 
Bohanon, H., Fenning, P., Carney, K., Minnis, M., Anderson-Harris, S., Moroz, K.,...Pigott, T. D. (2006). School-wide application of urban high school positive behavior support: A case study. Journal of Positive Behavior Interventions and Supports, 8(3), 131-145. doi: $10.1177 / 10983007060080030201$

Bradshaw, C. P., Mitchell, M. M., \& Leaf, P. J. (2010). Examining the effects of schoolwide positive behavioral interventions and supports on student outcomes: Results from a randomized controlled effectiveness trial in elementary schools. Journal of Positive Behavior Interventions, 12(3), 133-148. doi: 10.1177/1098300709334798

Detrich, R., Keyworth, R., \& States, J. (2007). Evidence-based education: Building an evidencebased culture. Journal of Evidence-Based Practices for Schools, 8(1), 26-44.

Fixen, D. L., \& Blasé, K. A. (2009). Implementation brief: Vol. 1. Chapel Hill, NC: National Implementation Research Network.

Fixsen, D. L., Blase, K. A., Horner, R., \& Sugai, G. (2009). Readiness for change: Scaling up brief \#3. Chapel Hill, NC: National Implementation Research Network.

Flannery, K. B., Fenning, P., Kato, M. M., \& Bohanon, H. (2011). A descriptive study of office disciplinary referrals in high schools. Journal of Emotional and Behavioral Disorders. Online First, doi: 10.1177/1063426611419512

Flannery, K. B., Guest, E., \& Horner, R. (2010). Schoolwide positive behavior support. Principal Leadership, 11(1), 38-43. doi: 2123461661

Gersten, R., Fuchs, L. S., Compton, D., Coyne, M., Greenwood, C., \& Innocenti, M. S. (2005). Quality indicators for group experimental and quasi-experimental research in special 
education. Exceptional Children, 71(2), 149-164. Retrieved from http:// www.cec.sped.org/

Gregory, A., \& Weinstein, R. S. (2008). The discipline gap and African Americans: Defiance or cooperation in the high school classroom. Journal of School Psychology, 46(4), 455-475. doi: $10.1016 /$ j.jsp.2007.09.001

Guba, E. G., \& Lincoln, Y. S. (1994). Competing paradiams in qualitative research. In N. K. Denzin \& Y. S. Lincoln (Eds.), Handbook of qualitative research (pp. xii, 643 p.). Thousand Oaks: Sage Publications.

Hawkins, S. M., \& Heflin, L. J. (2011). Increasing secondary teachers' behavior-specific praise using a video self-modeling and visual performance feedback intervention. Journal of Positive Behavior Interventions, 13(2), 97-108. doi: 10.1177/1098300709358110

Horner, R. H., Sugai, G., \& Anderson, C. M. (2010). Examining the evidence base for schoolwide positive behavior support. Focus on Exceptional Children, 42(8), 1-14. Retrieved from http://www.lovepublishing.com

Horner, R. H., Sugai, G., Smolkowski, K., Eber, L., Nakasato, J., Todd, A. W., \& Esperanza, J. (2009). A randomized, wait-list controlled effectiveness trial assessing school-wide positive behavior support in elementary schools. Journal of Positive Behavior Interventions, 11(3), 133-144. doi: 10.1177/1098300709332067

Horner, R. H., Todd, A. W., Lewis-Palmer, T., Irvin, L. K., Sugai, G., \& Boland, J. B. (2004). The school-wide evaluation tool (SET): A research instrument for assessing school-wide positive behavior support. Journal of Positive Behavior Interventions, 6(1), 3-12. doi: 10.1177/10983007040060010201 
Hunt, D., \& Sullivan, E. V. (1974). Between psychology and education. Hinsdale, Illinois: Dryden Press. https://isbndb.com/d/publisher/dryden_press.html

Irvin, L. K., Horner, R. H., Ingram, K., Todd, A. T., Sugai, G., Sampson, N. K., \& Boland, J. B. (2006). Using office discipline referral data for decision making about student behavior in elementary and middle schools: An empirical evaluation of validity. Journal of Positive Behavior Interventions, 8(1), 10-23. doi:

$10.1177 / 10983007060080010301$

Irvin, L. K., Tobin, T. J., Sprague, J. R., Sugai, G., \& Vincent, G. C. (2004). Validity of office discipline referral measures as indices of school-wide behavioral status and effects of school-wide behavioral interventions. Journal of Positive Behavior Interventions, 6(3), 131-147. doi: 10.1177/10983007040060030201

Knight, J. (2002). The teacher-guided professional development series (p. 78). Retrieved from http://www.kucrl.org/partnership/Documents/PartnershipLearningFieldbook.pdf

Kotter, J. (1995). Leading change: Why transformation efforts fail. Harvard Business Review, 73(2), 59-67. Retrieved from http://hbr.org/

Krueger, R. A., \& Casey, M. A. (2000). Focus groups: A practical guide for applied research (3rd ed.). Thousand Oaks, CA: Sage Publications, Inc.

Lohrmann, S., Martin, S. D., \& Patil, S. (2013). External and Internal Coaches' Perspectives About Overcoming Barriers to Universal Interventions. Journal of positive behavior interventions, 15(1), 26-38. doi: 0.1177/1098300712459078 
Matjasko, J. L. (2011). How effective are severe disciplinary policies?: School policies and offending from adolescence into young adulthood. Journal of School Psychology, 49(5), 555-572. doi: 10.1016/j.jsp.2011.05.002

Munk, D. D. (1994). The relationship between instructional variables and problem behavior: A review. Exceptional children, 60(5), 390.

National Center for Education Statistics. (2010). Indicators of school crime and safety: 2010. Retrieved from U. S. Department of Education, Institute of Education Sciences website: http://nces.ed.gov/programs/crimeindicators/crimeindicators2010/ind_19.asp t.

Patton, M. (1980). Qualitative evaluation methods. Beverly Hills, CA: Sage.

Ross, S. W., Romer, N., \& Horner, R. H. (2012). Teacher well-being and the implementation of school-wide positive pehavior interventions and supports. Journal of Positive Behavior Interventions, 14(2), 118-128. doi: 10.1177/1098300711413820

State Implementation \& Scaling-up of Evidence-Based Practices Project. (2012, September). Selecting the "what". SISEP eNotes. Retrieved from http://sisep.fpg.unc.edu/news/sisepenotes-september-2012

Scott, T. M., \& Barrett, S. (2004). Using staff and student time engaged in disciplinary procedures to evaluate the impact of school-wide PBS. Journal of Positive Behavior Interventions, 6(21), 21-28. doi: 10.1177/10983007040060010401

Siegel, S., \& Castellan, N. J., Jr. (1998). Nonparametric statistics for the behavioral sciences. New York, NY: McGraw-Hill. 
Sugai, G., Horner, R. H., Algozzine, R., Barrett, S., Lewis, T., Anderson, C.,...Simonsen, B. (2010). School-wide positive behavior support: Implementers'blueprint and selfassessment. Eugene, OR: University of Oregon. Retrieved from http:/www.pbis.org

Tay, R. S. (2001). Fatal crashes involving young male drivers: A continuous time poisson change-point analysis. Australian and New Zealand Journal of Public Health, 25(1), 2123. Retrieved from http://www.phaa.net.au/journal.php

Tyre, A., Feuerborn, L., \& Pierce, J. (2011). Schoolwide intervention to reduce chronic tardiness at the middle and high school levels. Preventing School Failure, 55(3), 132-139. doi: $10.1080 / 10459880903472918$

Vincent, C. G. (2011). The relationship between implementation of school-wide positive behavior support (SWPBS) and disciplinary exclusion of students from various ethnic backgrounds with and without disabilities. Journal of Emotional and Behavioral Disorders, 19(4), 217-232. doi: 10.1177/1063426610377329

Vincent, C., Spaulding, S., Tobin, T. J. (2010). A reexamination of the psychometric properties of the school-wide evaluation tool (SET). Journal of Positive Behavior Interventions, 12(3), 161-179. doi: 10.1177/1098300709332345 
Table 1.

Demographic Information for Treatment and Comparison schools FY07

\begin{tabular}{|c|c|c|c|c|}
\hline & \multicolumn{2}{|c|}{ Treatment Schools } & \multicolumn{2}{|c|}{ Control Schools } \\
\hline & $\mathrm{T} 1$ & $\mathrm{~T} 2$ & $\mathrm{C} 1$ & $\mathrm{C} 2$ \\
\hline Classroom Teacher FTE & 93 & 103 & 182 & 76 \\
\hline \# of Students & 1722 & 2342 & 3377 & 1587 \\
\hline$\underline{\text { School Type }}$ & Suburban & Suburban & Suburban & City \\
\hline \multicolumn{5}{|l|}{ Ethnicity } \\
\hline$\%$ Caucasian & 52 & 65 & 31 & 55 \\
\hline$\%$ African-American & 14 & 34 & 35 & 29 \\
\hline$\%$ Hispanic & 29 & 1 & 26 & 8 \\
\hline$\%$ Asian & 4 & 1 & 6 & 1 \\
\hline$\%$ Native American & 0 & 0 & 0 & 1 \\
\hline$\%$ Multiracial & 2 & 0 & 1 & 6 \\
\hline \% LEP & 0 & 0 & 0 & 2 \\
\hline \% Low SES & 29 & 35 & 34 & 45 \\
\hline$\%$ Attendance Rate & 89 & 91 & 86 & 89 \\
\hline$\%$ Mobility Rate & 18 & 29 & 28 & 17 \\
\hline \% Chronic Truancy Rate & 21 & 18 & 10 & 23 \\
\hline$\%$ Drop Out Rate & 3 & 5 & 3 & 2 \\
\hline$\%$ Graduation & 82 & 96 & 82 & 88 \\
\hline$\%$ SET Score* & 51 & 79 & 62 & 62 \\
\hline
\end{tabular}

Note*: Data were available for all schools on the SET for the 2006-2007 school year. 
Table 2.

Template for Analysis of Needs Assessment with School Teams

\section{Celebrations:}

- Some Components of Professional Learning Communities (PLC)

- Some Components for Use of Data

Common Themes Across All School Level Needs Assessments/Interviews:

- Effective Communication Concerns

- High Turnover of Staff

- Inconsistency of Defined Practices, Policy, and Procedures

- Outside Perception of School

- Professional Learning Communities

- School Climate Concerns

- Staff Buy-In

- Use of Data

\section{Unique Themes to Particular Groups:}

- Accommodations for Students from Diverse Backgrounds

- Expectation that All Teachers Should Teach Reading

- Staff Dedication

- Varied Work and Extracurricular Opportunities for Students

\section{Key Challenges for All Groups:}

- Academy Structure

- Effective Communication Concerns

- Inconsistency of Defined Practices, Policy, and Procedures

- School Climate and Safety Concerns

\begin{tabular}{l|l} 
Priorities/Next Steps: & Links to SWPBS Initiative: \\
\hline $\begin{array}{l}\text { Communicate and Support Academics and } \\
\text { Behavior Through PLCs }\end{array}$ & $\begin{array}{l}\text { Universal Supports-Academics and } \\
\text { Behavior, Healthy Teaming }\end{array}$ \\
\hline $\begin{array}{l}\text { Communication Systems for all Major } \\
\text { Stakeholders }\end{array}$ & Healthy Teaming, Communication \\
\hline $\begin{array}{l}\text { Define Expectations and Consequences for } \\
\text { Academics and Behavior }\end{array}$ & $\begin{array}{l}\text { Universal Supports-Academics and } \\
\text { Behavior-Communication }\end{array}$ \\
\hline Using Data for Data based Decision Making & $\begin{array}{l}\text { Universal Supports-Academics and } \\
\text { Behavior - healthy teaming, } \\
\text { Communication }\end{array}$ \\
\hline
\end{tabular}


District Team Development: Review current initiatives, connect SWPBS with district improvement plans, identify internal district coach, identify community partners, ensure professional development time for schools

School Team Development: Using model positions to identify: lead SWPBS administrator, internal coach, and chairs for SWPBS committees (i.e., teaching, acknowledgement, data, communications)
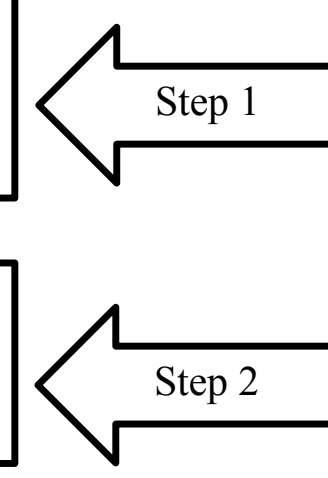

Needs Assessment: Interviews with groups of administrators, teachers, and non-certified staff. Collect and organize ODR data; complete Team Implementation Checklist, and Effective Behavior Support Data

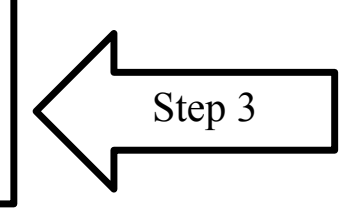

Initial Focused Training on SWPBS: Present needs assessment data (e.g., interviews, checklist, ODR), review current initiatives (e.g., working smarter), overview of healthy teaming, refine definitions for SWPBS committees, develop a year-at-a glance for PBS, action planning, integrating PBS expectations with core content, connecting expectations with instruction to

\section{Initial Training on High School SWPBS: Overview training for the} leadership team on the use of self-assessment data in action planning, high school specific examples of teaching, acknowledgment, and policies for handling student behavior (e.g., office vs. classroom management, tardy to class, redirection strategies), and running health teams
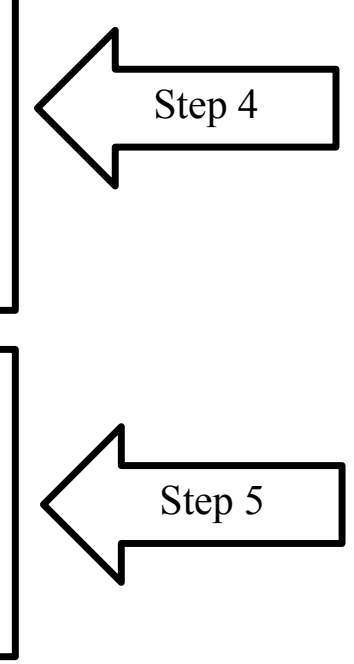

Leadership Team Training: Specific training for leadership team on (a) incorporating team processes for high schools (e.g., making decisions using data; systems, practices, and data components of SWPBS; action planning and communication), (b) establishing will and capacity among staff and team members (Israel \& Kasper, 2004), (c) working efficiently (Sugai \& Horner, 2009), and (d) building capacity

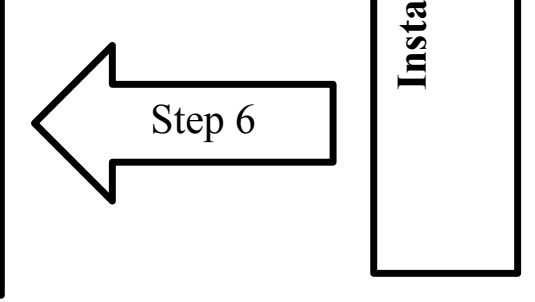

Figure 1. Stages for implementation. This figure provides descriptions of steps that can be taken to develop (or re-develop) support for implementation of SWPBS based on initial stages of implementation (SISEP, 2012). 